\title{
Modelling of the mechanical properties of concrete with cement ratio partially replaced by aluminium waste and sawdust ash using artificial neural network
}

\author{
U. Alaneme George ${ }^{1}$ (D) M. Mbadike Elvis ${ }^{1}$
}

Received: 3 August 2019 / Accepted: 14 October 2019/ Published online: 30 October 2019

(c) The Author(s) 2019 OPEN

\begin{abstract}
The use of aluminium waste (AW) and sawdust ash (SDA) in concrete was evaluated in this study where the cement ratio was partially replaced by fractions of AW and SDA introduced as a supplementary cementitious material. Artificial neural network (ANN) was adapted as the modelling tool for this study and was developed with a two-layer feed-forward network, hidden neurons with sigmoid activation function and linear output neurons for the simulation of the network. The setting time and concrete compressive strength at varying curing days were predicted using the neural network model with variations of constituents of the cement content consisting of OPC, SDA and AW as the input of the network. Three input and seven output data set were used for the model development using the following algorithms; Data Division: Random, Training: Levenberg-Marquardt and Calculation: MATLAB. The data sets are set aside for validation, training and testing; $70 \%$ of the samples are used for training, $15 \%$ for validation and $15 \%$ are also used for testing. The performance of the networks was evaluated using linear regression, RMSE and $R$-values. The model performance scored 0.91 and 0.07 for $R^{2}$ and RMSE, respectively, and performed better than the linear regression model, the results indicate the efficiency, reliability and usefulness of ANN for predicting concrete mechanical properties where AW and SDA are used to replace cement ratio accurately.
\end{abstract}

Keywords Alkali-silica reaction · Setting time $\cdot$ Compressive strength $\cdot$ Artificial neural network $\cdot$ MATLAB $\cdot$ Pozzolan

\begin{tabular}{|c|c|c|c|}
\hline & $3 d$ & 3-Day cured concrete compressive strength \\
\hline \multicolumn{2}{|c|}{ ANN Artificial neural network } & $7 d$ & 7-Day cured concrete compressive strength \\
\hline SCM & Supplementary cementitious Material & $28 d$ & 28-Day cured concrete compressive strength \\
\hline AW & Fraction of aluminium waste & $60 d$ & 60-Day cured concrete compressive strength \\
\hline SDA & Fraction of saw dust ash & $90 d$ & 90-Day cured concrete compressive strength \\
\hline OPC & Fraction of ordinary Portland cement & & \\
\hline Initial ST & Initial setting time & & \\
\hline Final ST & Final setting time & 1 Ir & duction \\
\hline $\mathrm{C}-\mathrm{S}-\mathrm{H}$ & Calcium silicate hydrate & & \\
\hline ALEX & Aluminium extrusion industry Inyishi & & entary cementitious materials (SCM) devel- \\
\hline RMSE & Root mean square error & & essential to the advancing economical con- \\
\hline ASR & Alkali-silica reaction & & materials to be used in the construction of a \\
\hline
\end{tabular}

Electronic supplementary material The online version of this article (https://doi.org/10.1007/s42452-019-1504-2) contains supplementary material, which is available to authorized users.

U. Alaneme George, tinz2020@gmail.com | ${ }^{1}$ Civil Engineering Department, Michael Okpara University of Agriculture, Umudike, P. M. B. 7267, Umuahia 440109, Abia State, Nigeria. 
self-sufficient means of shelter. Concrete in its basic form is the mixture of cement paste and aggregates. Cement is the major cementitious material in concrete but recently, SCM is introduced in the concrete mixtures which complements the cementitious component proportion in concrete [1]. These materials are generally by-products from other processes or natural materials. Some of these materials are called pozzolans, which are class of siliceous and aluminous materials and by themselves do not possess any cementitious properties but when in finely divided format in the presence of water, chemically reacts with calcium hydroxide at ordinary temperature to form compounds possessing cementitious properties [2].

In concrete, the aggregates have to be chemically inert so as not to react with the concrete caustic pore solution. However, when the aggregates are not inert, they react with the alkali hydroxides ions in concrete, causing expansion and cracking over a period time. The use of pozzolans in the concrete mixture to partially replace the cement ratio can mitigate alkali-silica reaction (ASR) by reducing the alkalinity of the pore fluid due to reduced quantity of cement and by pozzolanic activity. The pozzolanic reaction mechanism is a process of detachment of silicate anions from the reactive aggregate by hydroxyl ions from cement in the pore fluid. Sodium and potassium ions are the ions readily available in concrete to balance the reactive amorphous silicate anions and an alkali-silicate gel is formed. The alkali-silicate gel is unstable in the presence of calcium ions forming stable calcium silicate hydrate $(\mathrm{C}-\mathrm{S}-\mathrm{H})[3,4]$. In pozzolanic reaction, the particles are in finely divided state as there is much calcium available in the cement paste, there is a formation of alkali-silicate gel forms in a thin layer around the pozzolanic particle which then quickly converts to $\mathrm{C}-\mathrm{S}-\mathrm{H}$ resulting in no expansion and reduction in cracks due to the pozzolanic activity mitigating ASR in concrete [5].

ASR is a swelling reaction that occurs over time in concrete between the highly alkaline cement paste and the reactive non-crystalline silica found in many common aggregates given sufficient moisture. It is a reaction between alkali, water and amorphous silica. When the ASR is in the starting stage, the effect on compressive strength is less but when the ASR reaction is more, there is a huge loss of compressive strength [6]. ASR is one of the most troubling deterioration mechanism in concrete; the cracks can take years to appear and they can allow other deterioration mechanism to destroy concrete. There can be enough water inside the concrete to fuel ASR. The cement paste has a very high $\mathrm{pH}$, which means a lot of hydroxide ions. The $\mathrm{pH}$ attacks the aggregates causing a gel to be formed. The gel absorbs water and expands swells and this causes cracking once the ASR gels starts to expands, it causes the concrete to crack. As the cracks grows wider as more gels were formed, the gels then flows through the cracks and eventually gets to the outside of the concrete to stain the concrete. The importance of properly using SCMs is not only to mitigate ASR, but also to enhance its resistance to other durability challenges, such as, reinforcement corrosion, sulphate attack, freezing and thawing $[7,8]$.

ANN is a techniques which mimic the processing manner of a human brain and it deals with nonlinear and complex generalization. It make use of different layers of mathematical processing and activation functions to make generalization of the information it's fed. The network have the capacity to learn from experience and they need to do so with the aid of tremendous amount of information thrown at them called the training set. It learns through a process of re-adjustments of the weighted parameters between the processing elements and element parameters [9-11]. ANN are increasingly adapted to solve numerous civil engineering and material science problems due to the generation of a model with robust performance. To overcome the setbacks of empirical approach, artificial neural network (ANN) which has scored attention due to its flexibility has been implemented in various engineering applications in modelling of nonlinear multivariate interrelationships of the behaviour of concrete strength and setting time [12].

Paulson et al. [13], experimentally optimized the replacement extent of cement content with silica fume; the compressive strength of silica fume concrete was predicted using artificial neural network (ANN). The constituent materials added for production of concrete are taken as inputs. The ANN was trained with the experimental data till the Mean Square Error (MSE) was consistent at improved performance of the model.

Aref et al. [14], research on the effect of volcanic scoria (VS) on the properties of concrete. Twenty-one concrete mixes with three water-cement ratios $(0.5,0.6$, and 0.7$)$ and seven replacement levels of VS $(0 \%, 10 \%, 15 \%, 20 \%$, $25 \%, 30 \%$, and $35 \%$ ) were produced. Water permeability, compressive strength, and the porosity of the concrete were investigated. Artificial neural networks (ANNs) were used for prediction of the investigated properties using feed-forward back-propagation neural network. The use of ANN models provided a more accurate tool to capture the effects of five parameters (cement content, volcanic scoria content, water content, super plasticizer content, and curing time) on the investigated properties.

Hocine et al. [15], In their research, optimum content of supplementary cementing materials (SCMs) such as limestone filler (LF) is used to blend with Portland cement which resulted in many environmental and technical advantages, such as enhancement of sustainability in concrete industry, increase in physical properties and reducing $\mathrm{CO}_{2}$ emission are well known. Artificial neural networks (ANNs) was 
applied in the work using feed-forward back-propagation algorithm and transfer function of Tan-sigmoid for training the network. The training, testing and validation of data during the back-propagation training process yielded good correlations exceeding $97 \%$. The results of this study revealed that the proposed ANNs model showed a high performance as a feasible and highly efficient tool for simulating the LF concrete compressive strength prediction.

\section{Neural networks}

ANN are basically inspired by the neurons of a human brain which are similarly to a new born baby, as he/she learns from experience and we want the neural network to do that very quickly. The building block of a neural network is the neuron. ANN works in a similar way with the biological neural system; design to simulate and generalize large sets of data the same way the human brain analyses and processes the information [16]. An Artificial Neural Network Application provides an alternative way to solve complex problems; it is among the newest signal processing technologies. Artificial neural networks offer real solutions which are difficult to match with other technologies. Neural network based solution is very efficient in terms of development, time and resources. The input/ output training data is fundamental for the networks as it communicates the information that will be necessary to discover the optimal operating point. A nonlinear nature of neural network makes its processing elements flexible in their system [17]. The self-learning ability of the network enable it to generate better results as more data becomes available [18]. So if you train your network with more data, the more accurate the model output. A neural network is a combination of different features which evaluates the various input features to find patterns and data generalization using a neural network architecture [19]. ANN consists of five main parts; Inputs are information which enters the neuron. Weights are values that amplify or de-amplify the effect of an input signal. Sum function is a function which evaluates the effect of inputs and weights absolutely in the network. We have to multiply each input with the given edge weight and have to add these values together [20].

sum $=\sum_{i=0}^{n} x_{i} w_{i}$

where $x_{i}$ is the input parameters and $w_{i}$ is the edge weights.

The activation function is going to converts the results from the sum function depending on the type utilized. A step function activation function will output 1 if the input is higher than a certain threshold and 0 when otherwise.
Whenever we have neurons connected to other neurons; in calculating the output, we first use the sum function that is sum up the incoming signals and then the activation function is going to take this sum that have been calculated by the sum function. The activation function is going to decide whether the neuron gets fired or not [21,22].

In general, for multiple layer feed-forward models the sigmoid activation function is used. The output of the neuron is computed using Eq. (2) with a sigmoid activation function as follows

(output) $=\frac{1}{1+\mathrm{e}^{-\alpha(\text { sum })}}$

where $a$ is the constant of proportionality used to control the slope of the semi-linear region.

\subsection{Artificial neurons}

ANN are computing systems that are inspired by the brains neural network, these networks are based on collection of connected units called artificial neurons. Each connection between these neurons can transmit a signal from one neuron to another. The receiving neuron then processes the signal and signals the downstream neurons connected to it [23]. Neurons are typically organized in layers, different layers may perform different transformations in the inputs and signals are essentially transferred from the first layer also known as the input layer to the last layer which is the output layer; in between the input and output layers we have the hidden layer. The neuron is an artificial node which performs the necessary tasks of taking the input from the preceding nodes, applying the learning techniques to generate the edge weights. The sum function add up the input signals multiplied by their respective edge weights and then pass the sum to an activation function which evaluates the composite prediction or probabilities to produce the output signal. These generation of fused predictions is what happens to every node in a neural network and because of this, the predictions for ANN are progressively processed until the final output is obtained. For a given neuron, let there be $m+1$ inputs with signals $x_{0}$ through $x_{m}$ and weights $w_{0}$ through $w_{m}$. Usually, the $x_{0}$ input is assigned the value +1 , which makes it a bias input with $w_{k 0}=b_{k}$. This leaves only $m$ actual inputs to the neuron: from $x_{1}$ to $x_{m}[24,25]$.

The output of the $k$ th neuron is:

$y_{k}=\varphi\left(\sum_{j=0}^{m} w_{k j} x_{j}\right)$

where $\varphi$ is the transfer function.

The structure of a perceptron which is the basic unit of an artificial neuron network is shown in Fig. 1 which shows the structure of a typical neuron with the basic 
components and the activation functions. The way it processes information with the model of the human's nervous system. Suppose we have some inputs coming from one end, biologically these are equivalent to the dendrites; then, we have the input vectors multiplying the weights to get the linear combination; from there we move to the stage of nonlinearity which is taking care of using activation functions. The output is analogous to the axon of a biological neuron, and its value propagates to the input of the next layer, through a synapse. It may also exit the system, possibly as part of an output vector [26].

\subsection{Learning of the ANN}

This is the major phase in neural network development, the progressive re-adjustments of the weighted parameters is called training which is done by either allocating weights evaluated from the training data set or by adjusting the weights with respect to same criterion automatically [27]. ANN's learning rule or learning process is an algorithm or mathematical logic which enhances the network's performance and better generalization of the data sets. It is done by updating the weights and bias which are adjustable parameters when a network is simulated using a specific data environment. A learning rule will adopt existing conditions (biases and weights) of the network after training and will compare the observed results and measured results of the network to produce new and improved values for bias and weights [28].

\subsubsection{Types of learning in ANN}

The most relevant features of artificial neural networks is their capability of learning from the presentation of

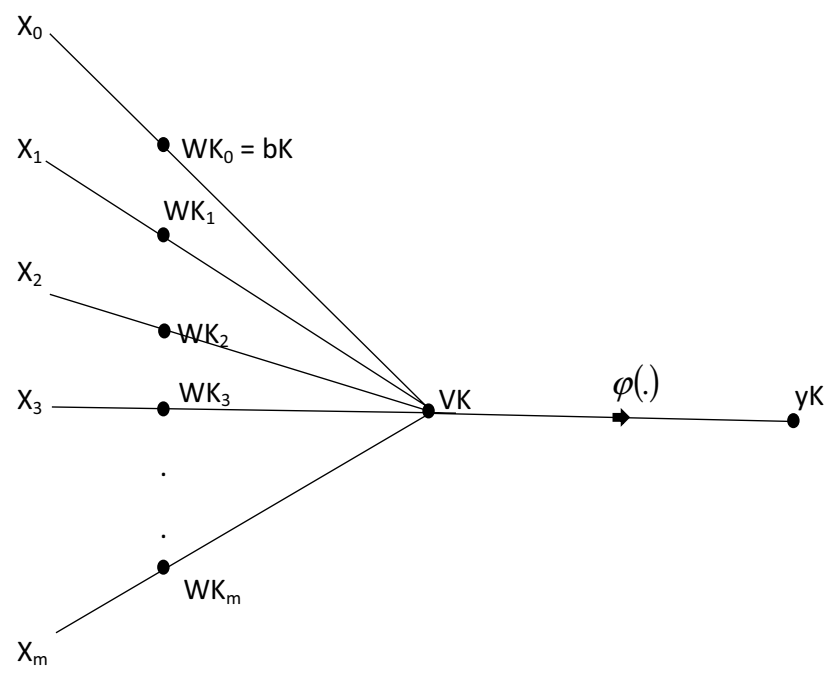

Fig. 1 The structure of a neuron samples data sets (patterns), which expresses the system behaviour. This is accomplished by presenting the network with a number of training samples. Once the network has learned the relationship between inputs and outputs, it can generalize solutions, meaning that the network can produce an output which is close to the expected (or desired) output of any given input values. The training process of a neural network involves applying the required ordinate steps for tuning the synaptic weights and thresholds of its neurons, in order to generalize the solutions produced by its outputs. The set of ordinate steps used for training the network is called learning algorithm. During its execution, the network will thus be able to extract discriminate features about the system being mapped from samples acquired from the system [29-31].

Depending upon the process to develop the network, the various types of ANN are explained in Table 1.

\subsection{Back propagation}

We try to minimize the weights of the neurons for those that are contributing more to the error and this happens while tracking back the neurons of the neural network, and finding where the error lies. This learning process is called back propagation. Because we mainly have control of the weights we can use back propagation to minimize the predicted error of a neural network by adjusting the weights simultaneously $[36,37]$. We propagate from the opposite down to the input layer and adjusting the weights to minimize the error and answers the question; how far are we from the output? We go back and adjust the weights slowly so that we get a smaller error in the next forward-propagation integration and we repeat the process for all the inputs and outputs in the training data set until the error that we get is very small for which is sufficient for our application [38]. The major feature of back propagation is its recursive, efficient and iterative method for evaluating the weights updates in order to improve the network performance. In the context of learning, back propagation is used by the stochastic gradient descent optimization to update the adjustable parameters by calculating the gradient of the loss function [39].

\subsection{Multiple linear regression}

Multiple linear regression (MLR) is a statistical method used to generate relationship between several independent variables and a dependent variable. In MLR, the predicted value which is a continuous dependent variable $Y$ is a linear transformation of one or more independent variables $X$ such that the sum of squared deviations of the predicted $Y$ and observed parameter is a minimum. With three independent variables, as presented in this paper, the prediction of $Y$ is expressed by the following formula:

SN Applied Sciences 
Table 1 Types of learning in ANN [32-35]

\begin{tabular}{|c|c|}
\hline Supervised learning & $\begin{array}{l}\text { Where the training data set is the input to the network and measured output is known; weights are adjusted until } \\
\text { optimum yield design value. Supervised learning is a case of pure inductive inference, where the free variables } \\
\text { of the network are adjusted by knowing a priority, i.e. the desired outputs for the investigated system. Just as the } \\
\text { case of learning from a teacher }\end{array}$ \\
\hline Unsupervised learning & $\begin{array}{l}\text { The input data set is used to train the neural network until the output is known. The output classifies the input } \\
\text { data and adjust the weights by feature instruction in the input data. No dependent variable is provided, the } \\
\text { resulting map of cases is based on the intrinsic similarities of the input data. The most common unsupervised } \\
\text { networks are Kohonen networks (Self Organizing Maps); it uses no external teacher and is based upon only local } \\
\text { information. It is also referred to as self-organization, in the sense that it self-organizes data presented to the } \\
\text { network and detects their emergent collective properties }\end{array}$ \\
\hline Reinforcement learning & $\begin{array}{l}\text { This is when the output is unknown but the network provides a feedback whether the input is right or wrong, } \\
\text { it is a semi-supervised learning. The learning algorithms used on reinforcement learning adjusts the internal } \\
\text { neural parameters relying on any qualitative or quantitative information acquired through the interaction with } \\
\text { the system (environment) being mapped, using this information to evaluate the learning performance. Several } \\
\text { learning algorithms used by reinforcement learning are based on stochastic methods that probabilistically select } \\
\text { the adjustment actions, considering finite set of possible solutions that can be rewarded if they have chances of } \\
\text { generating satisfactory results }\end{array}$ \\
\hline Offline learning & $\begin{array}{l}\text { It is when the adjustment of the weight vectors and threshold is do everything after training is presented to the } \\
\text { network. It is also known as batch learning. Networks using offline learning requires, at least, one training epoch } \\
\text { for executing one adjustment step on their weights and thresholds. Hence, all training samples must be available } \\
\text { during the whole learning process }\end{array}$ \\
\hline Online learning & $\begin{array}{l}\text { The adjustment of the weight vectors and the threshold is done only after presenting each sample to the network. } \\
\text { It is used when the behaviour of the system being mapped changes rapidly, thus the adoption of offline learning } \\
\text { is almost impractical because the samples used at a given moment may no more represent the system behaviour } \\
\text { in posterior moments. However, since patterns are presented one at a time, weight and threshold adjustment } \\
\text { actions are well located and punctual, and they reflect a given behavioural circumstance of the system. There- } \\
\text { fore, the network will begin to provide accurate responses after presenting a significant number of samples }\end{array}$ \\
\hline
\end{tabular}

$Y=b_{0}+b_{1} X_{1}+b_{2} X_{2}+b_{3} X_{3}$

where $b_{i}$ values are called regression weights and are calculated in a way that minimizes the sum of squared deviations and $X_{i}$ are the independent variables [40].

\subsection{Optimization algorithm}

In optimization of a design, the design objective could be simply to maximize the efficiency of production or to minimize the cost of production. An optimization algorithm is a procedure which is executed iteratively by comparing various solutions till an optimum or a satisfactory solution is found. With the advent of computers, optimization has become a part of computer-aided design activities. Optimization algorithms helps us to maximize or minimize an objective function which is simply a mathematical function dependent on the model's internal learnable parameters which are used in computing the target values from the set of predictors used in the model. The weights and the bias values of the neural network which is its internal learnable parameters are used in computing the output values and are learned and updated in the direction of optimal solution [41].

All optimization algorithms require the user to supply a starting point, usually denoted by $X_{0}$, starting from $X_{0}$, optimization algorithms generate a sequence of iterates $X_{1}, X_{2}, X_{3}, \ldots X_{k}, X_{k+1}, \ldots$

The process of iteration terminates when either no more progress can be made or when it seems that solution has been approximated with sufficient accuracy.

For moving from the current iterate $X_{k}$, to a new iterate $X_{k+1}$, trusted region method is the continuous optimization algorithms used in the neural network modelling. Most of the continuous optimization algorithms follow either Line Search Method or Trust-Region Method [42, 43].

\section{Experimental program}

Concrete mixtures with varying proportions of AW and AW/SDA replacement ranging from 0 to $40 \%$ were investigated in order to ascertain its compressive strength. We intend to evaluate the effect of SDA and AW which are industrial wastes in concrete; the rate of strength gain is very rapid during the first 28 days of casting after which it then slows down. The reason for this is the presence of water. The water helps to facilitate the hydration process by dissolving the cement minerals, but it also contributes ions, in the form of hydroxyl groups $(\mathrm{OH}-)$, to the hydration products.

Concrete gains compressive strength swiftly in its initial days after casting, up to $90 \%$ in only 14 days. Then, 
its strength have reached $99 \%$ in 28 days, still concrete continues to gain strength after that period, but that rate of gain in compressive strength is very less compared to that before 28 days. In carrying out these tests we intend to find out the effect of hydration periods on the compressive strength so as to understand the method of strength development of the concrete mixes $[26,44,45]$.

The target characteristic strength of $35 \mathrm{~N} / \mathrm{mm}^{2}$ with a cement content of $290 \mathrm{~N} / \mathrm{mm}^{2}$, a coarse aggregate content of $1198.65 \mathrm{~kg} / \mathrm{m}^{3}$, a fine aggregate content of $766.35 \mathrm{~kg} /$ $\mathrm{m}^{3}$ and a water-cement ratio of 0.45 . The AW was obtained from Aluminium Extrusion Industry (ALEX), Inyishi in lkeduru L.G.A., Imo State, Nigeria. It is produced by heating aluminium scraps at a temperature of $1980^{\circ} \mathrm{C}$ in a furnace. The waste is then sieved through a $150 \mu \mathrm{m}$ sieve size so as to obtain the particles of waste in a finely divided state. On the other hand, SDA was obtained from timber at Owerri, Imo State. The saw dust was burned in a control incineration and sieve with $150 \mu \mathrm{m}$ sieve size.

To achieve the purpose of this research, cementitious portion of the concrete will be partially replaced by varying ratios of AW and SDA and the mechanical properties and setting time evaluated and modelled using ANN. The mixes were cast using $150 \mathrm{~mm} \times 150 \mathrm{~mm} \times 150 \mathrm{~mm}$ cube sizes. After $24 \mathrm{~h}$, the specimen were demoulded and cured in $\mathrm{Ca}(\mathrm{OH})_{2}$ saturated distilled water. The curing were done at 3, 7, 28, 60 and 90 days, respectively. Fragments of some of the broken paste specimens were tested to detect their composition by X-ray diffractometry (XRD) and their microstructures by scanning electron microscopy (SEM).

\subsection{Data processing}

The multiple layer perceptron (MLP) is the type of neural network used for this research study with feed-forward back-propagation algorithm development incorporated in a computer program for the ANN simulation, MATLAB software. Different architectures were tried through which the appropriate structure was determined for the data sets which includes determination of the number of hidden layer's neurons. Levenberg-Marquardt training algorithm is the training algorithm used; in which training is automatically halted when generalization cease to improve, and indicated by an increase in the mean square error of the validation samples. Levenberg-Marquardt algorithm is a very efficient technique used in nonlinear least square programing with unconstrained or unbounded constrained problems for finding minima, and performs well on most test functions. This method usually have more rapid convergence than other algorithms. But this algorithms need to maintain large matrixes in memory and requires a lot of space. It is basically used for the solution of the nonlinear regression problems. The performance of the ANN model is then tested using coefficient of determination, $R^{2}$ and means of root mean squared error, RMSE. Gradient descent algorithm back-propagation learning rule is employed with activation functions as logarithmic sigmoid (logsig) and tangent sigmoid (tansig) for the training and validation $[46,47]$.

\subsection{Methods}

\subsubsection{Compressive strength}

To determine the compressive strength of concrete, cement and fine aggregates were mixed thoroughly; after mixing, the concrete cubes measuring $150 \mathrm{~mm} \times 150 \mathrm{~mm}$ $x 150 \mathrm{~mm}$ were lubricated to reduce friction between the concrete and the cube mould. By the use of scoop, the cubes were filled to the brim and compacted also. The compaction was done in three layers; after the concrete had gained sufficient strength $(24 \mathrm{~h})$, the concrete cubes will then be demoulded and were taking inside the curing tank. The concrete cubes were cured for 3, 7, 28, 60 and 90 days, respectively. At the end of each curing period, the concrete cubes were crushed and the average strength recorded [48].

\subsubsection{Setting time test}

The setting time laboratory experiment was conducted in accordance with BS12 [49] using vicat apparatus. It uses final and initial setting pins to determine the initial and final setting time, respectively. The initial setting pin is $1.13 \pm 0.05 \mathrm{~mm}$ in diameter. The final setting pin has a circular cutting edge $5 \mathrm{~mm}$ diameter (outer pin) and set $0.5 \mathrm{~mm}$ (inner pin) behind the tip of the needle. Initial setting time is that time period between the time water is added to cement and time at which $1 \mathrm{~mm}$ square section needle fails to penetrate the cement paste, placed in the Vicat's mould 5-7 mm from the bottom of the mould. Final setting time is that time period between the time water is added to cement and the time at which $1 \mathrm{~mm}$ needle makes an impression on the paste in the mould but $5 \mathrm{~mm}$ attachment does not make any impression [50].

\section{- The procedure}

1. Before commencing setting time test, do the consistency test to obtain the water required to give the paste normal consistency $(P)$.

2. Take $400 \mathrm{~g}$ of cement and prepare a neat cement paste with $0.85 P$ of water by weight of cement.

3. Gauge time is kept between 3 and $5 \mathrm{~min}$. Start the stop watch at the instant when the water is added to the cement. Record this time $\left(t_{1}\right)$. 
4. Fill the Vicat mould, resting on a glass plate, with the cement paste gauged as above. Fill the mould completely and smooth off the surface of the paste making it level with the top of the mould. The cement block thus prepared is called test block.

- Initial setting time

1. Place the test block confined in the mould and resting on the non-porous plate, under the rod bearing the needle.

2. Lower the needle gently until it comes in contact with the surface of test block and quick release, allowing it to penetrate into the test block.

3. In the beginning the needle completely pierces the test block. Repeat this procedure i.e. quickly releasing the needle after every $2 \mathrm{~min}$ till the needle fails to pierce the block for about $5 \mathrm{~mm}$ measured from the bottom of the mould. Note this time $\left(t_{2}\right)$.

- Final Setting Time

1. For determining the final setting time, replace the needle of the Vicat's apparatus by the needle with an annular attachment.

2. The cement is considered finally set when upon applying the final setting needle gently to the surface of the test block; the needle makes an impression thereon, while the attachment fails to do so. Record this time $\left(t_{3}\right)$.

- Calculation

Initial setting time $=t_{2}-t_{1}$

Final setting time $=t_{3}-t_{1}$,

where $t_{1}=$ time at which water is first added to cement, $t_{2}=$ time when needle fails to penetrate $5-7 \mathrm{~mm}$ from bottom of the mould, $t_{3}=$ Time when the needle makes an impression but the attachment fails to do so.

\subsection{Microstructural and mineralogical analysis}

Experiments were carried out to determine the effect of SDA and AW on setting time and compressive strength of the cement paste and mortar, respectively. X-ray diffractometry (XRD) and scanning electron microscopy (SEM) were applied to assess the change of the hydrated phases. The XRD of the paste at different hydration processes shows that $0 \%$ replacement of cement with SDA and AW had a typical hydration process. The peaks of $\mathrm{Ca}(\mathrm{OH})_{2}$ diminished the XRD patterns and their intensity increased with time. With those of $\mathrm{C}_{3} \mathrm{~S}$ also decreased with time. With increasing addition of SDA and AW, the peaks of $\mathrm{Ca}(\mathrm{OH})_{2}$ decreased in intensity. Whereas the highest peak in $0 \%$ replacement of cement with SDA and AW corresponded to that of $\mathrm{Ca}(\mathrm{OH})_{2}$, it nearly disappeared in $40 \%$ replacement of cement with SDA and AW. The XRD pattern of $40 \%$ replacement of cement with SDA and AW at different hydration periods were essentially the same, except for some differences in intensity.

The typical microstructures of the paste were evaluated by SEM observation. The observation indicated that a large amount of $\mathrm{C}-\mathrm{S}-\mathrm{H}$ gel occurred in $5 \%$ replace of cement with SDA and AW at 3 days of hydration. This gel not only formed dense surface coverage on the cement particles but also developed in the pores. A similar structure was observed in $10 \%, 20 \%, 30 \%$ and $40 \%$ replacement of cement with SDA and AW. In contrast, only traces of $\mathrm{C}-\mathrm{S}-\mathrm{H}$ gel can be observed that massive $\mathrm{Ca}(\mathrm{OH})_{2}$ grew through regions of C-S-H gel in $0 \%$ replacement of cement with SDA and AW at 90 -day hydration period, but $\mathrm{Ca}(\mathrm{OH})_{2}$ did not survive in mature hydrated paste ( $40 \%$ replacement of SDA and AW).

The setting time of cement paste is recognized to be caused by the increasing volume of hydration products. This process leads to a decrease in the distance between individual particles until plastic flow is restricted by cohesive forces. Although some research reports that setting is controlled by crystallization of ettringite, most accept the importance of alite hydration, especially for normal setting. It is reasonably deduced that the setting of the pastes with SDA and AW is primarily attributed to the formation of $\mathrm{C}-\mathrm{S}-\mathrm{H}$ attributed to the formation of $\mathrm{C}-\mathrm{S}-\mathrm{H}$ resulting from $\mathrm{C}_{3} \mathrm{~S}$ hydration as well as reaction between $\mathrm{Ca}(\mathrm{OH})_{2}$ and SDA and AW. As SDA and AW have high pozzolanic activity, they will react with $\mathrm{Ca}(\mathrm{OH})_{2}$ released by hydration of $\mathrm{C}_{3} \mathrm{~S}$ to form $\mathrm{C}-\mathrm{S}-\mathrm{H}$. The presence of $\mathrm{Ca}(\mathrm{OH})_{2}$ deposits may weaken the bonds between hydration particles as well as between cement and aggregates. With increasing amounts of SDA and $\mathrm{AW}, \mathrm{Ca}(\mathrm{OH})_{2}$ diminished or fully disappeared and transformed into $\mathrm{C}-\mathrm{S}-\mathrm{H}$. This observation suggested that weaker points in the mortar due to the occurrence of $\mathrm{Ca}(\mathrm{OH})_{2}$ have been eliminated while at the same time the content of $\mathrm{C}-\mathrm{S}-\mathrm{H}$ increased. This may be why addition of SDA and AW increases the strength of the mortar significantly.

\subsection{Performance measure}

The model results were analysed using computer statistical software SPSS 25.0 to determine the goodness of fit and loss function parameter such as, root mean square error (RMSE) calculated using Eqs. (6-7), where $n$ denotes the number of instances presented to the model and $M_{i}$ 
and $P_{i}$ represents measured and predicted output, respectively; the results were calculated and used to evaluate the performance of ANN model.

$\mathrm{RMSE}=\sqrt{\left(\frac{\sum_{i=1}^{n}\left(M_{i}-P_{i}\right)^{2}}{n}\right)}$

$R^{2}=\left(\frac{n \sum x y-\sum x \sum y}{\sqrt{n \sum x^{2}-\left(\sum x\right)^{2}} \sqrt{n \sum y^{2}-\left(\sum y\right)^{2}}}\right)^{2}$

RMSE is the standard deviation of the difference between the measured and predicted outputs known as residuals or prediction errors. These residuals enable us measure how far we are from the regression line data points. RMSE also help us to evaluate the measure of how spread out these residuals are from the fitted line. There is a direct relationship between RMSE and $R$-values; if the RMSE is 0 then the correlation coefficient is 1 and vice versa, because all of the points lie on the regression line signifying minimum or no errors [51]. Coefficient of determination is a measure of how much of the variance in the observed values of the dependent variables can be explained by its relationship to the independent variable. It is the percentage of the variation explained by the linear regression. It is calculated by squaring the Pearson correlation coefficient value. It is the ratio of two sums of squares identities. It can take values from 0 to 1 , the closer the value is to 1 , the better explanatory power of the independent variable [52].

\subsection{Data set used for the model development}

The experimental results obtained from laboratory methodology to evaluate the mechanical properties of the concrete with respect to varying proportions of AW and SDA to partially replace the cement content in the cementitious portion of the concrete. The bar chart shown in Figs. 2, 3 and 4 gives a detailed insight of the general data constituting a total of thirty data set.

Figure 2 shows the various mix ratios of the ingredients namely; OPC, SDA and AW. We have the number of runs (30). The OPC ratio was dominant while varying ratios of AW and SDA ranging from 0 to $40 \%$. These values represent the ratios for the mixture components which is why it is used as the input parameter of the neural network.

Figure 3 shows the setting time of the cement paste with respect to the mixture ratios of the ingredients in seconds, and Fig. 4 shows the compressive strength of concrete at varying hydration periods in $\mathrm{N} / \mathrm{mm}^{2}$ ranging from 3 to 90 days. The experimental responses were further used in developing the model as the target parameter. The rate of strength gain with respect to different hydration periods was evaluated for the concrete mixed with AW and SDA.

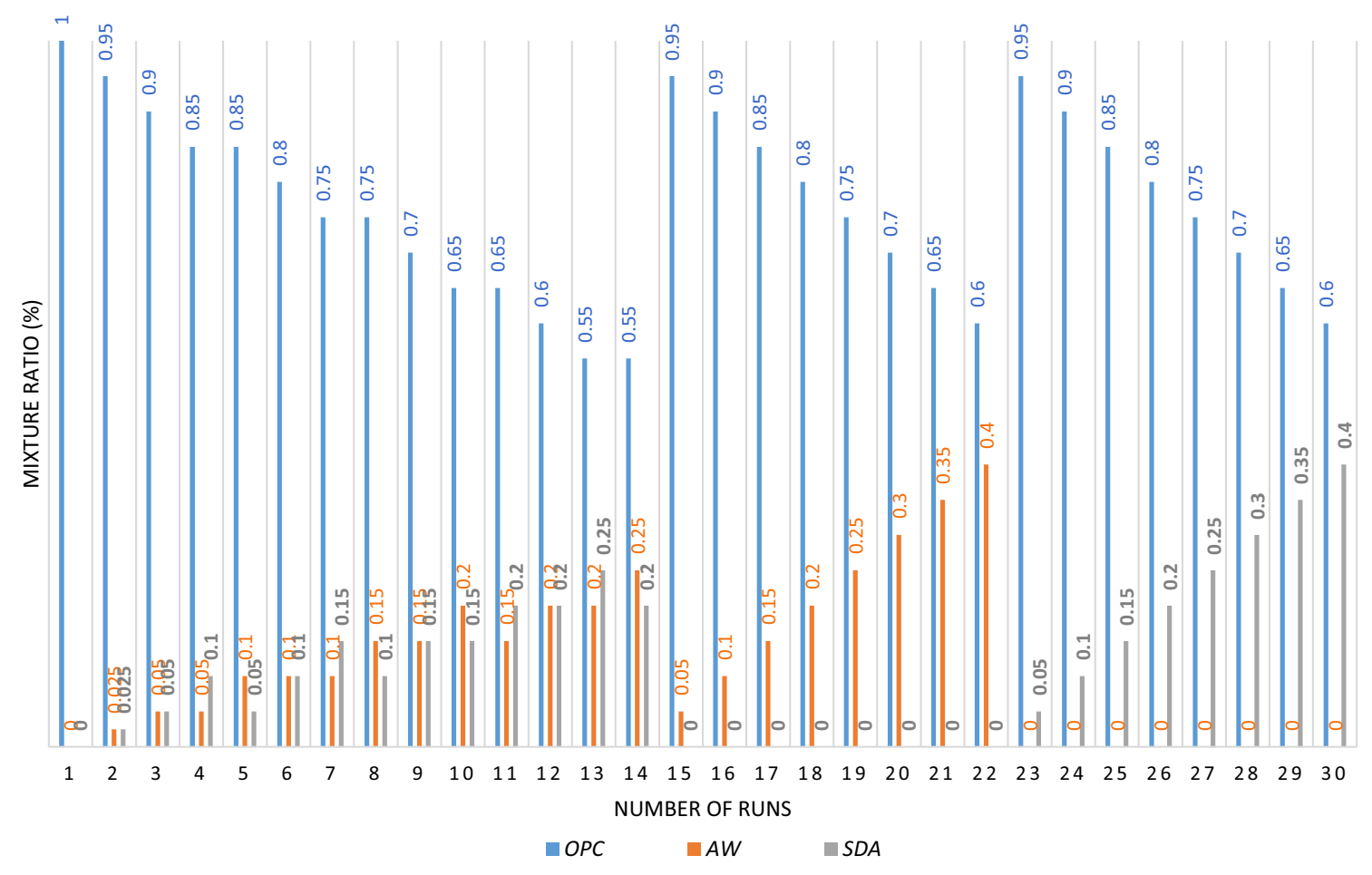

Fig. 2 The input data 


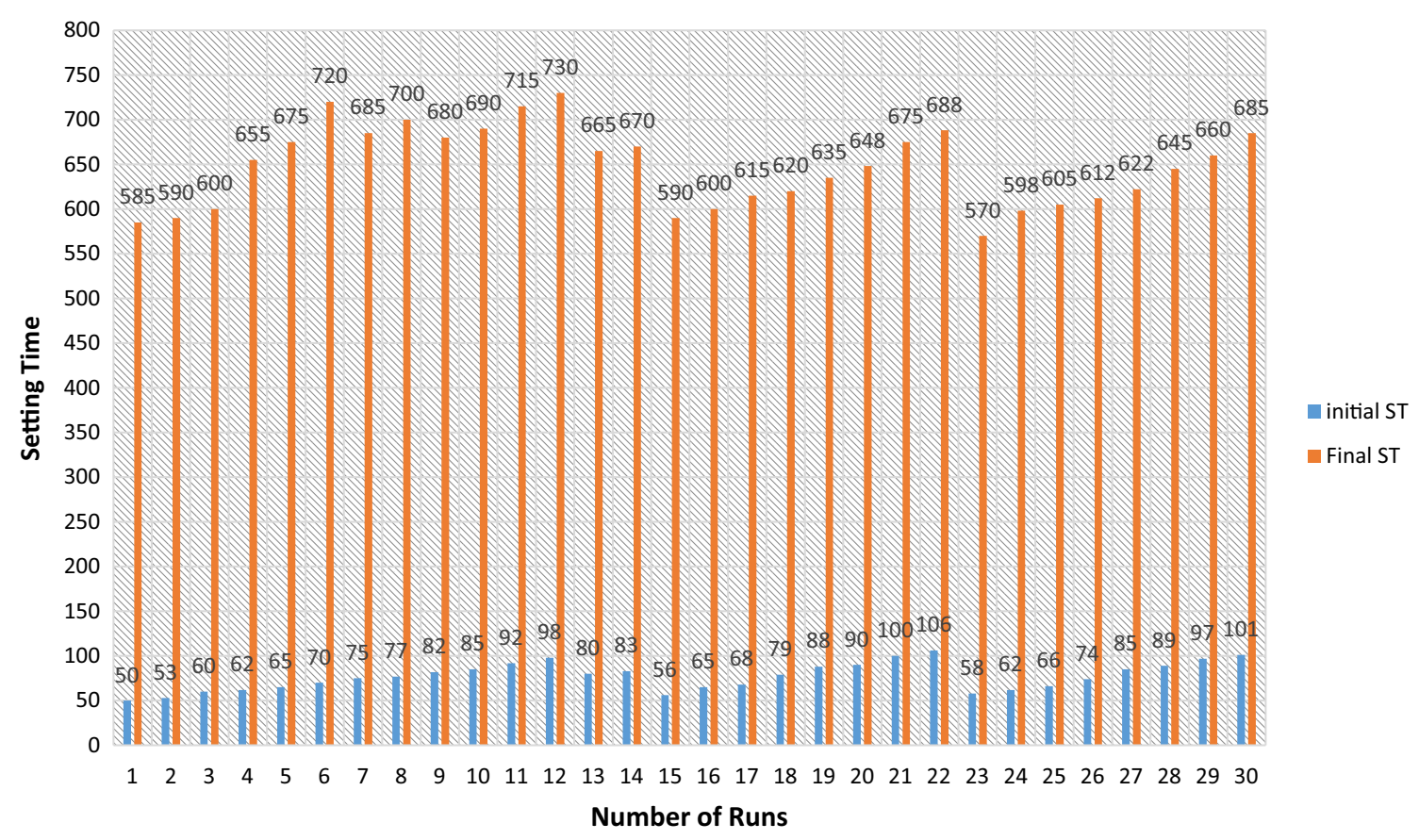

Fig. 3 Target data setting time of the concrete

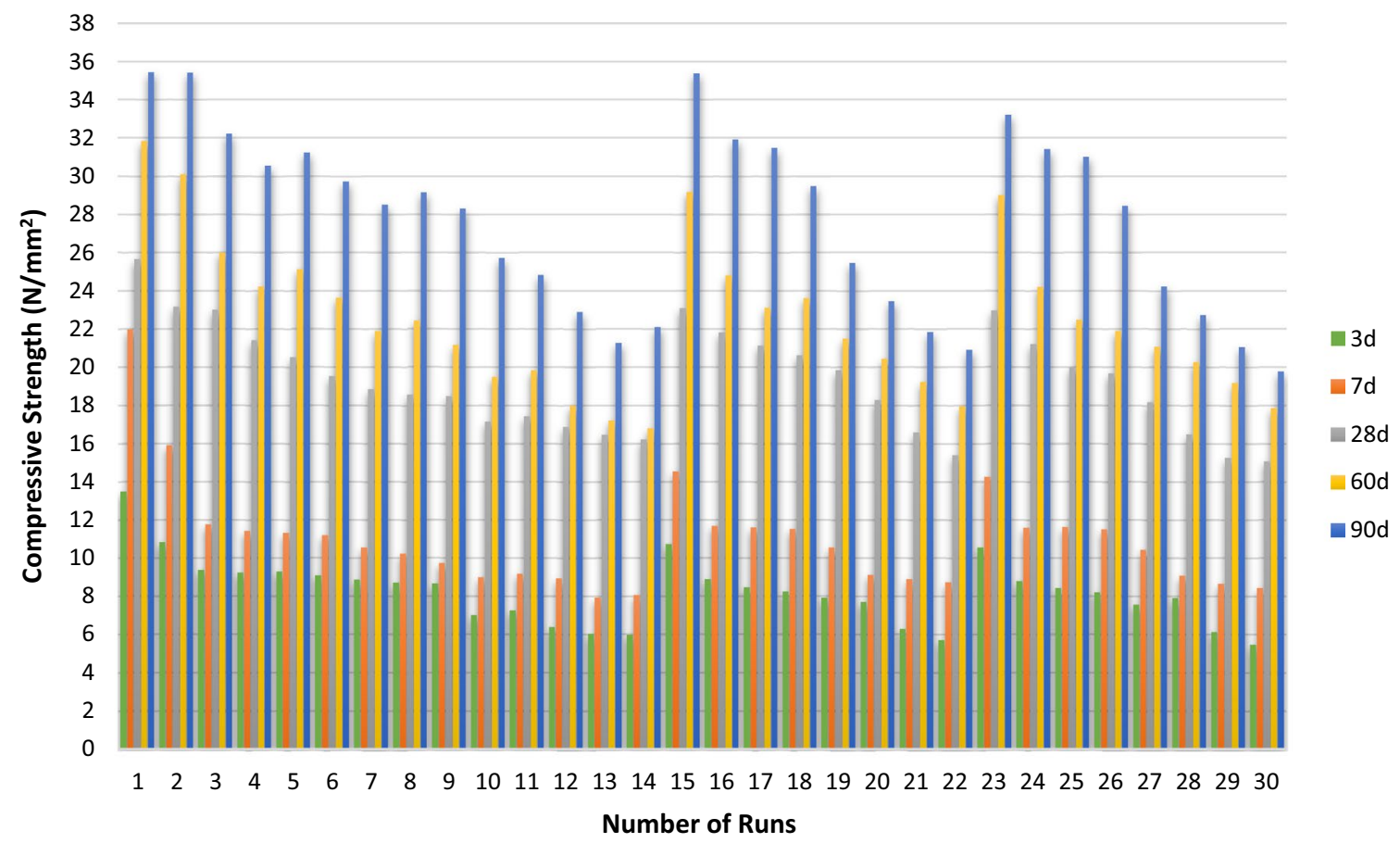

Fig. 4 Target data compressive strength of the concrete with respect to varying hydration periods

The descriptive statistics of the result obtained from laboratory tests used for the ANN model development are presented in Table 2.

\section{Results and discussion}

The chemical and physical characteristics of AW and SDA shows that AW contains high percentage of $\mathrm{SiO}_{2}$ 
Table 2 Statistical parameters of data sets used for training the ANN

\begin{tabular}{|c|c|c|c|c|c|c|c|}
\hline Input/output parameters & Mean & Standard error & $\begin{array}{l}\text { Standard } \\
\text { deviation }\end{array}$ & Sample variance & Range & Minimum & Maximum \\
\hline OPC (\%) & 0.765 & 0.024 & 0.129 & 0.017 & 0.450 & 0.550 & 1.000 \\
\hline AW (\%) & 0.118 & 0.021 & 0.115 & 0.013 & 0.400 & 0.000 & 0.400 \\
\hline SDA (\%) & 0.118 & 0.021 & 0.115 & 0.013 & 0.400 & 0.000 & 0.400 \\
\hline Initial ST (mins) & 77.200 & 2.846 & 15.586 & 242.924 & 56.000 & 50.000 & 106.000 \\
\hline Final ST (mins) & 647.600 & 8.194 & 44.878 & 2014.041 & 160.000 & 570.000 & 730.000 \\
\hline $3 \mathrm{~d}\left(\mathrm{~N} / \mathrm{mm}^{2}\right)$ & 8.236 & 0.324 & 1.774 & 3.148 & 8.040 & 5.450 & 13.490 \\
\hline $7 \mathrm{~d}\left(\mathrm{~N} / \mathrm{mm}^{2}\right)$ & 10.977 & 0.517 & 2.830 & 8.009 & 14.050 & 7.910 & 21.960 \\
\hline $28 \mathrm{~d}\left(\mathrm{~N} / \mathrm{mm}^{2}\right)$ & 19.285 & 0.501 & 2.744 & 7.532 & 10.570 & 15.070 & 25.640 \\
\hline $60 \mathrm{~d}\left(\mathrm{~N} / \mathrm{mm}^{2}\right)$ & 22.442 & 0.712 & 3.899 & 15.205 & 15.010 & 16.810 & 31.820 \\
\hline $90 \mathrm{~d}\left(\mathrm{~N} / \mathrm{mm}^{2}\right)$ & 27.626 & 0.880 & 4.820 & 23.230 & 15.680 & 19.750 & 35.430 \\
\hline
\end{tabular}

Table 3 Physical and chemical properties of AW and SDA

\begin{tabular}{|c|c|c|}
\hline Property & AW & SDA \\
\hline Moisture content \% & 0.28 & 0.36 \\
\hline Specific gravity & 3.39 & 2.4 \\
\hline Bulk density $\left(\mathrm{kg} / \mathrm{m}^{3}\right)$ & 776 & 846 \\
\hline $\mathrm{PH}$ & 8.2 & 9.7 \\
\hline $\mathrm{MgO}(\%)$ & 0.5 & 5.8 \\
\hline $\mathrm{Fe}_{2} \mathrm{O}_{3}(\%)$ & 0.26 & 2.3 \\
\hline $\mathrm{Na}_{2} \mathrm{O}(\%)$ & 0.36 & 5.8 \\
\hline $\mathrm{SiO}_{2}(\%)$ & 56.58 & 67.2 \\
\hline $\mathrm{ZnO}_{2}(\%)$ & 0.79 & 0 \\
\hline $\mathrm{MnO}(\%)$ & 0.56 & 0.01 \\
\hline Loss in ignition & 6.4 & 4.67 \\
\hline $\mathrm{SO}_{4}(\%)$ & $\mathrm{Nil}$ & Nil \\
\hline $\mathrm{CuO}(\%)$ & Trace & Nil \\
\hline $\mathrm{TiO}_{2}(\%)$ & Trace & Nil \\
\hline $\mathrm{Al}_{2} \mathrm{O}_{3}(\%)$ & 15.89 & 4.1 \\
\hline $\mathrm{CdO}(\%)$ & Trace & Nil \\
\hline $\mathrm{K}_{2} \mathrm{O}(\%)$ & Nil & 0.1 \\
\hline $\mathrm{SO}_{2}(\%)$ & Nil & 0.5 \\
\hline $\mathrm{CaO}(\%)$ & 18.2 & 10 \\
\hline $\mathrm{P}_{2} \mathrm{O}_{5}(\%)$ & Nil & 0.5 \\
\hline
\end{tabular}

(56.58\%), $\mathrm{Al}_{2} \mathrm{O}_{3}(15.89 \%)$ and $\mathrm{CaO}(18.2 \%)$ while that of SDA has a higher percentage of $\mathrm{SiO}_{2}(67.2 \%), \mathrm{MgO}(5.8 \%)$ and $\mathrm{CaO}(10 \%)$. The loss in ignition is 6.4 and $4.67 \mathrm{for}$ AW and SDA, respectively; the full chemical composition analysis results are shown in Table 3.

\subsection{ANN model development}

Figures 5, 6, 7, 8 and 9 are the results gotten from MATLAB software. The structure of the ANN performed in this research, a two-layer feed-forward network, the activation functions used are the sigmoid transfer function in

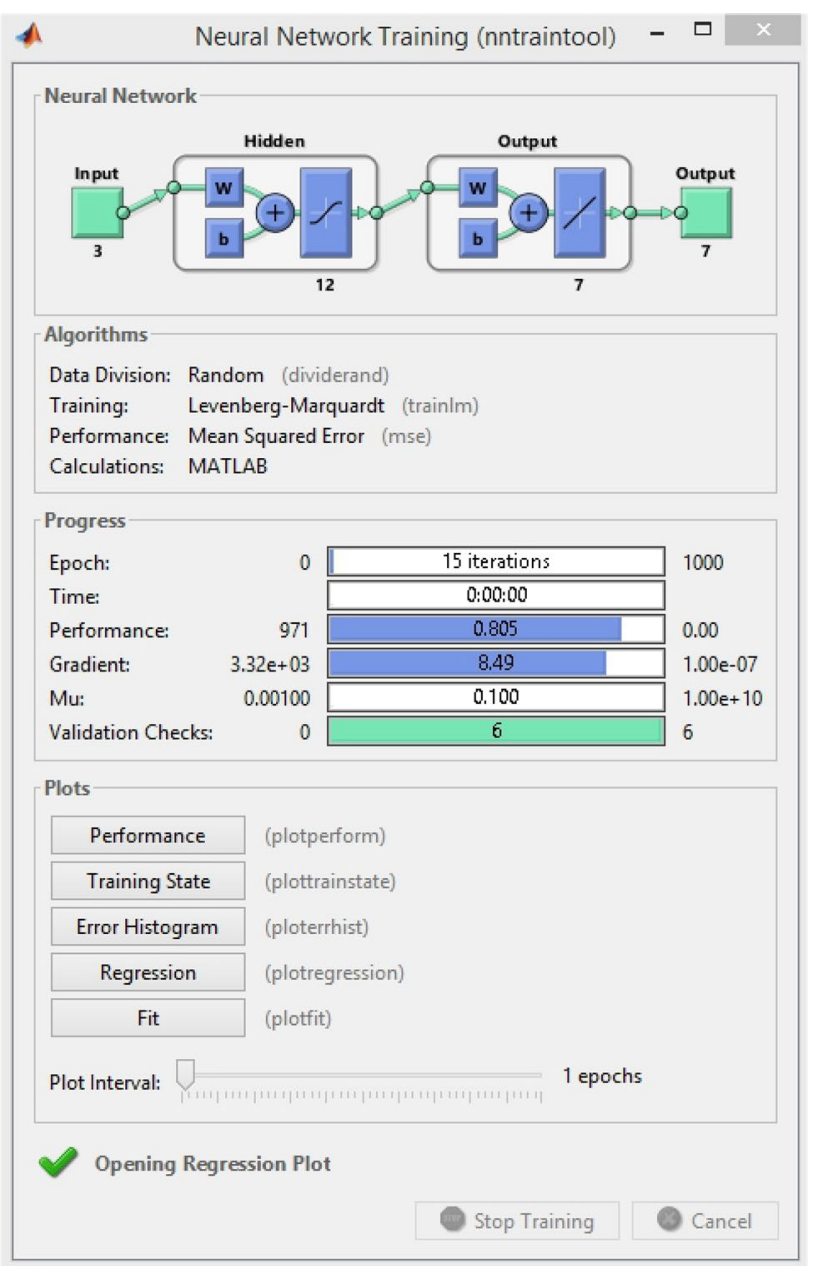

Fig. 5 The ANN architecture

the hidden layer, and a linear transfer function in the output layer is shown in Fig. 2. The network architecture is 3-12-7 with OPC, AW and SDA ratio of the cementitious component of the concrete the input parameter while 

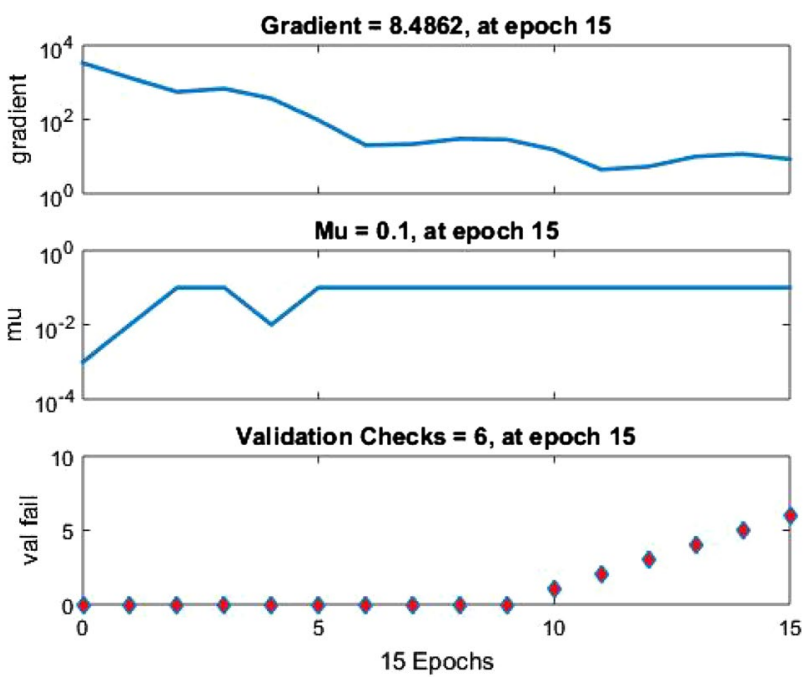

Fig. 6 ANN training state

the output parameters are the final and initial setting time and the concrete compressive strength for curing days of $3,7,28,60$ and 90 , respectively. The generalization of the data set will help us evaluate the performance of AW and SDA replacing cement content in concrete. To achieve this purpose, the input parameters are the cementitious portion of the concrete which will be partially replaced by varying proportions of AW and SDA while the output parameters are the response of the mixture with respect to setting time and compressive strength with varying hydration periods.

\subsubsection{ANN training state}

Figure 6 shows the training state for the ANN model; the errors are repeated 6 times after epoch 9 and the test was stopped at epoch 15 with the gradient of 8.486. The error is repeated starting from epoch 10 demonstrated over-fitting of the data. Therefore, epoch 9 is selected as the base and its weights are chosen as the final weights. Moreover, the validation check is 6 at epoch 15, because the errors are repeated 6 times before the process finally stopped.

\subsubsection{ANN validation performance}

Figure 7 shows the mean squared error and validation performance of the network starting at a large value and descending to a small value. The training, validation, and

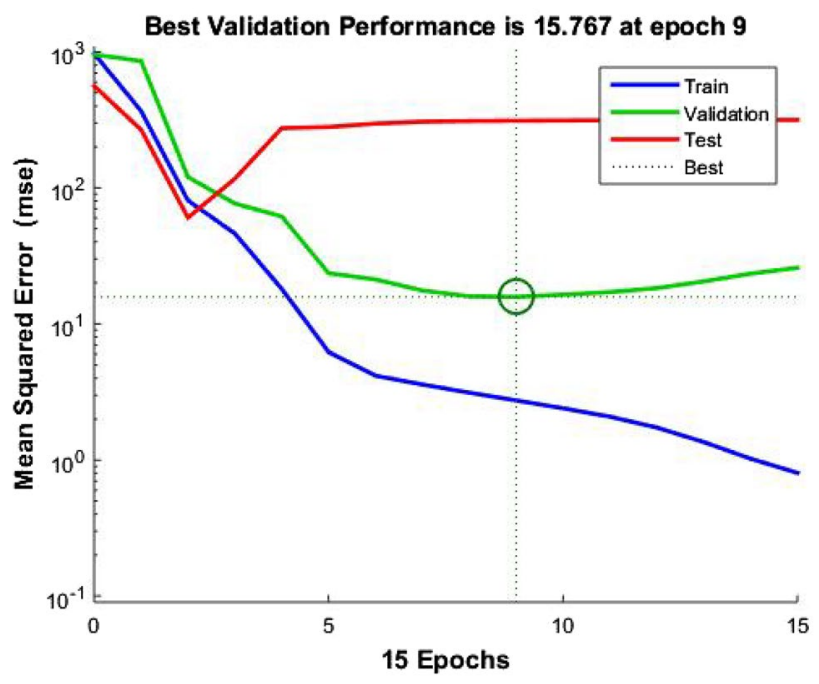

Fig. 7 Validation performance of the ANN

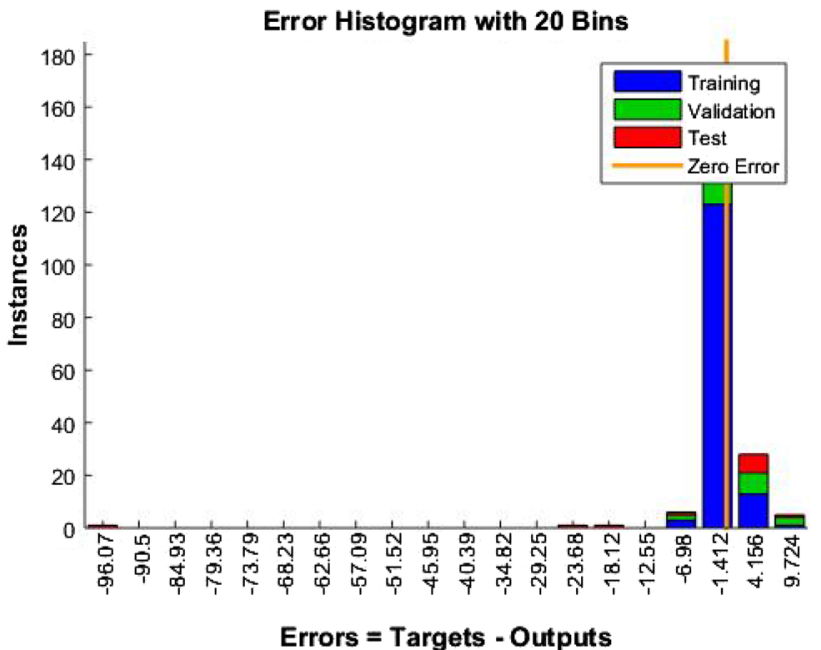

Fig. 8 ANN error histogram

test were displayed in the plot. The optimal validation performance is 15.767 at 9 epoch after 6 error repetitions, the process is ended at epoch 15 as shown in the $x$-axis of the plot.

\subsubsection{ANN error histogram}

Figure 8 presents the error histogram chart with 20 bins for the validation, test and training, in ANN modelling. As it is shown in the figure, the zero error is indicated with a yellow line in the middle with 120 instances in the training set. 
Fig. 9 Regression plot for training, test and validation of the ANN
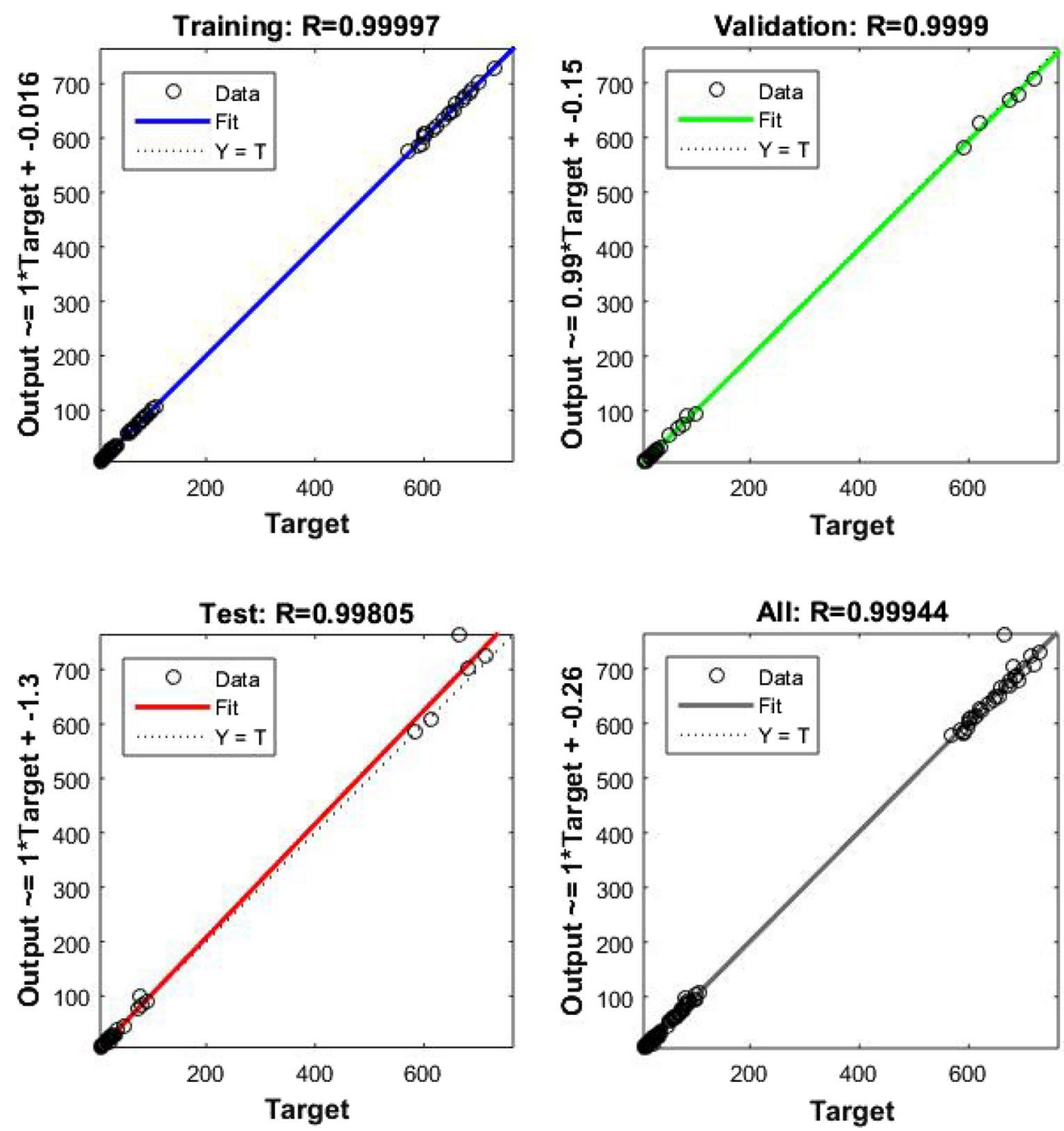

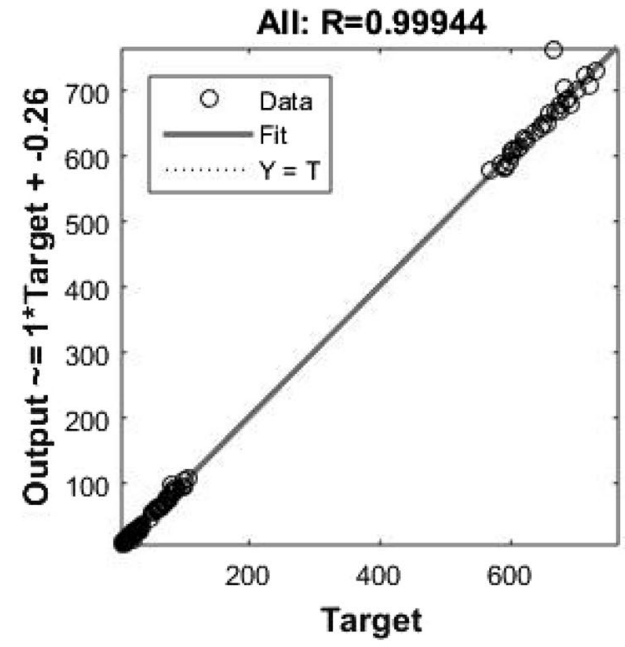

\subsubsection{ANN regression plot}

Figure 9 shows the coincidence between the target and response variables which is the coefficient of determination for validation, training and test steps, respectively. $\mathrm{R}$-values is a statistical evaluation of how close the data sets are to the fitted regression line. The "Target" values as displayed in the regression plots imply the "Measured" values and the "Output" values represent the "Predicted" values. From the regression plot, the $R$-values confirms acceptable accuracies of the model in both the training and validation steps.

\subsection{Regression model calculations}

The multiple regression analysis results showing the model summary, regression coefficients and RMSE is presented in Table 4. From the results, the model exhibits and average and non-robust performance.

\subsection{ANN model validation}

The performance of ANN model in predicting the setting time and 3-, 7-, 28-, 60- and 90-day compressive strength of concrete is evaluated using $\mathrm{R}$-values and RMSE. Figure 10 shows the residual output line of fit plot for initial ST with $R^{2}=0.9273$ and equation of line of fit is $y=0.9339 x+4.5984$.

Figure 11 shows the residual output line of fit plot for Final ST with $R^{2}=0.8514$ and equation of line of fit is $y=0.8319 x+105.84$ indicating a satisfactory performance of the model as shown below.

Figure 12 shows the residual output line of fit plot for 3-day compressive strength with $R^{2}=0.8597$ and equation of line of fit is $y=1.1975 x-1.4714$.

Figure 13 shows the residual output line of fit plot for 7-day compressive strength with $R^{2}=0.9346$ and equation of line of fit is $y=1.037 x-0.2554$. 
Table 4 Regression analysis results

Fig. 10 Initial setting time line of fit plot

Fig. 11 Final setting time line of fit plot

\begin{tabular}{|c|c|c|c|c|c|c|c|c|c|}
\hline & \multicolumn{4}{|c|}{ Model summary } & \multicolumn{4}{|c|}{ Regression coefficients } & \multirow[b]{2}{*}{ RMSE } \\
\hline & $S$ & $R$-Sqd & $R$-Sqd adj & $R$-Sqd pred & Constant & OPC & AW & SDA & \\
\hline Initial ST & 5.499 & 88.84 & 87.55 & 84.42 & -734 & 7.8 & 8.96 & 8.85 & 2.3 \\
\hline Final ST & 24.76 & 72.71 & 69.57 & 64.02 & 4250 & -36.44 & -33.76 & -34.07 & 4.1 \\
\hline $3 d$ & 0.592 & 90.01 & 88.85 & 86.22 & 92.3 & -0.806 & -0.932 & -0.936 & 11 \\
\hline $7 d$ & 1.524 & 73.99 & 70.99 & 61.87 & 83.7 & -0.678 & -0.864 & -0.869 & 7.2 \\
\hline $28 d$ & 0.65 & 94.45 & 94.45 & 93.13 & 90.3 & -0.658 & -0.844 & -0.881 & 5.5 \\
\hline $60 d$ & 1.064 & 92.56 & 92.56 & 90.99 & 109.4 & -0.795 & -1.079 & -1.094 & 8 \\
\hline $90 d$ & 1.14 & 94.98 & 94.4 & 93.34 & 218 & -1.808 & -2.148 & -2.185 & 6.4 \\
\hline
\end{tabular}
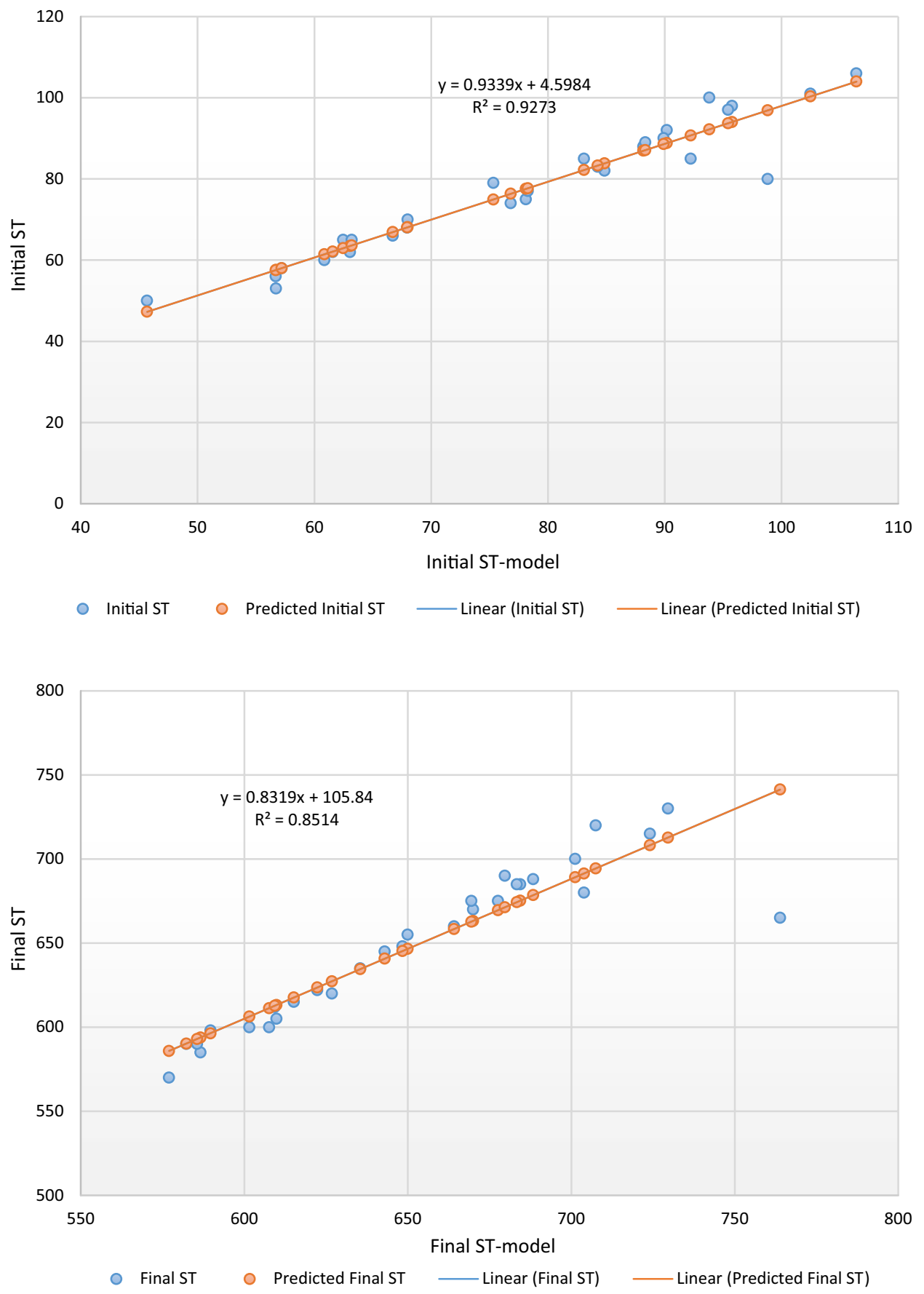

SN Applied Sciences 
Fig. 12 3-Day cured concrete compressive strength line of fit plot
Fig. 13 7-Day cured concrete compressive strength line of fit plot
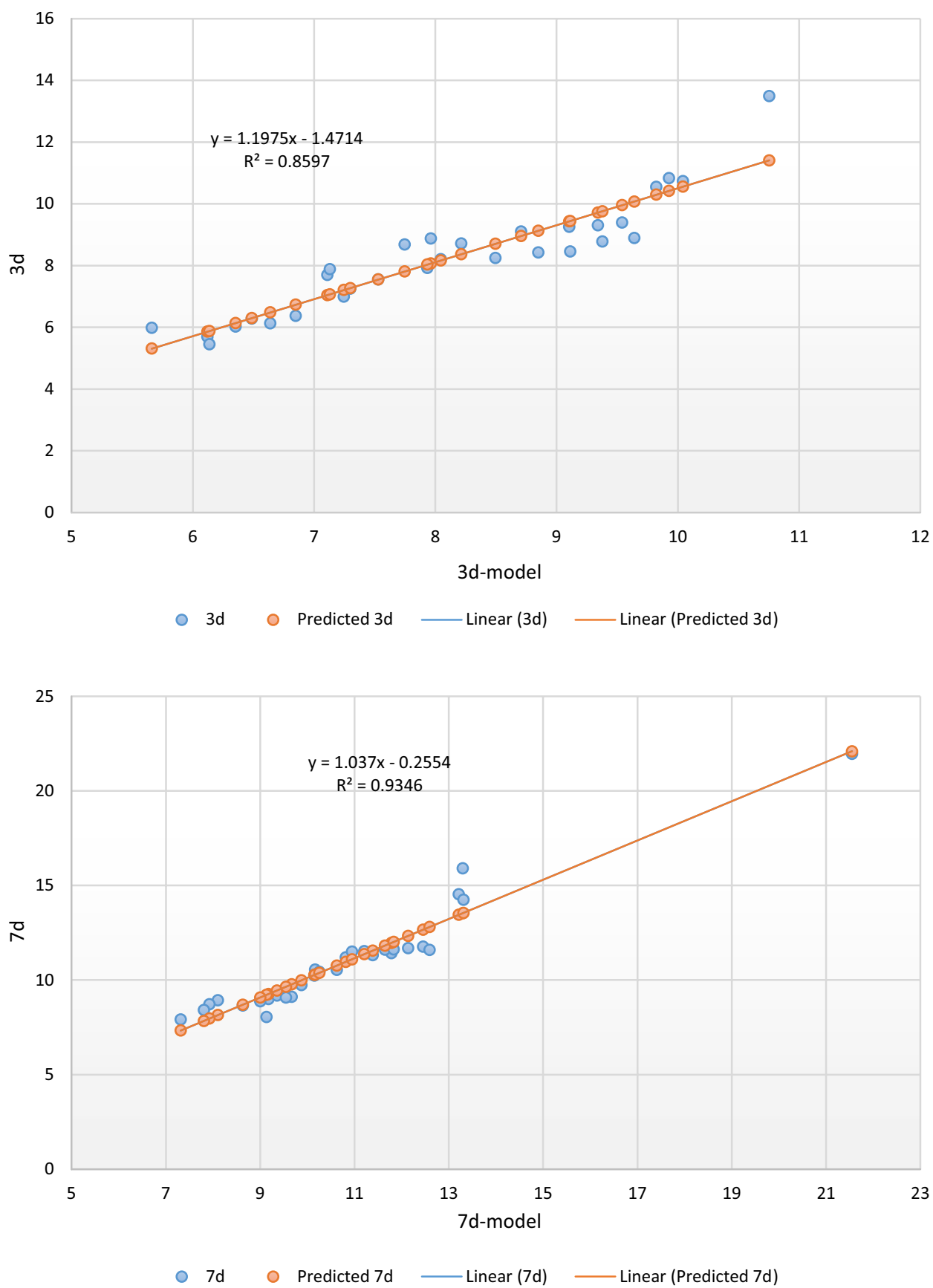

Figure 14 shows the residual output line of fit plot for 28-day compressive strength with $R^{2}=0.9452$ and equation of line of fit is $y=1.0189 x-0.2159$.

Figure 15 shows the residual output line of fit plot for 60-day compressive strength with $R^{2}=0.8831$ and equation of line of fit is $y=1.1236 x-2.396$.

Figure 16 shows the residual output line of fit plot for 90-day compressive strength with $R^{2}=0.9516$ and equation of line of fit is $y=1.0044 x-0.0641$.
Table 5 shows the root mean square error (RMSE) which is the standard deviation of the residuals (prediction errors). Consequently, the combined use of $\mathrm{R}$ and RMSE was found to yield a sufficient assessment of ANN model performance and allows comparison of generalization accuracy of the predicted ANN model performance. This combination also reveals that there is no significant difference between the measured and predicted output parameters. 
Fig. 14 28-Day cured concrete compressive strength line of fit plot
Fig. 15 60-Day cured concrete compressive strength line of fit plot
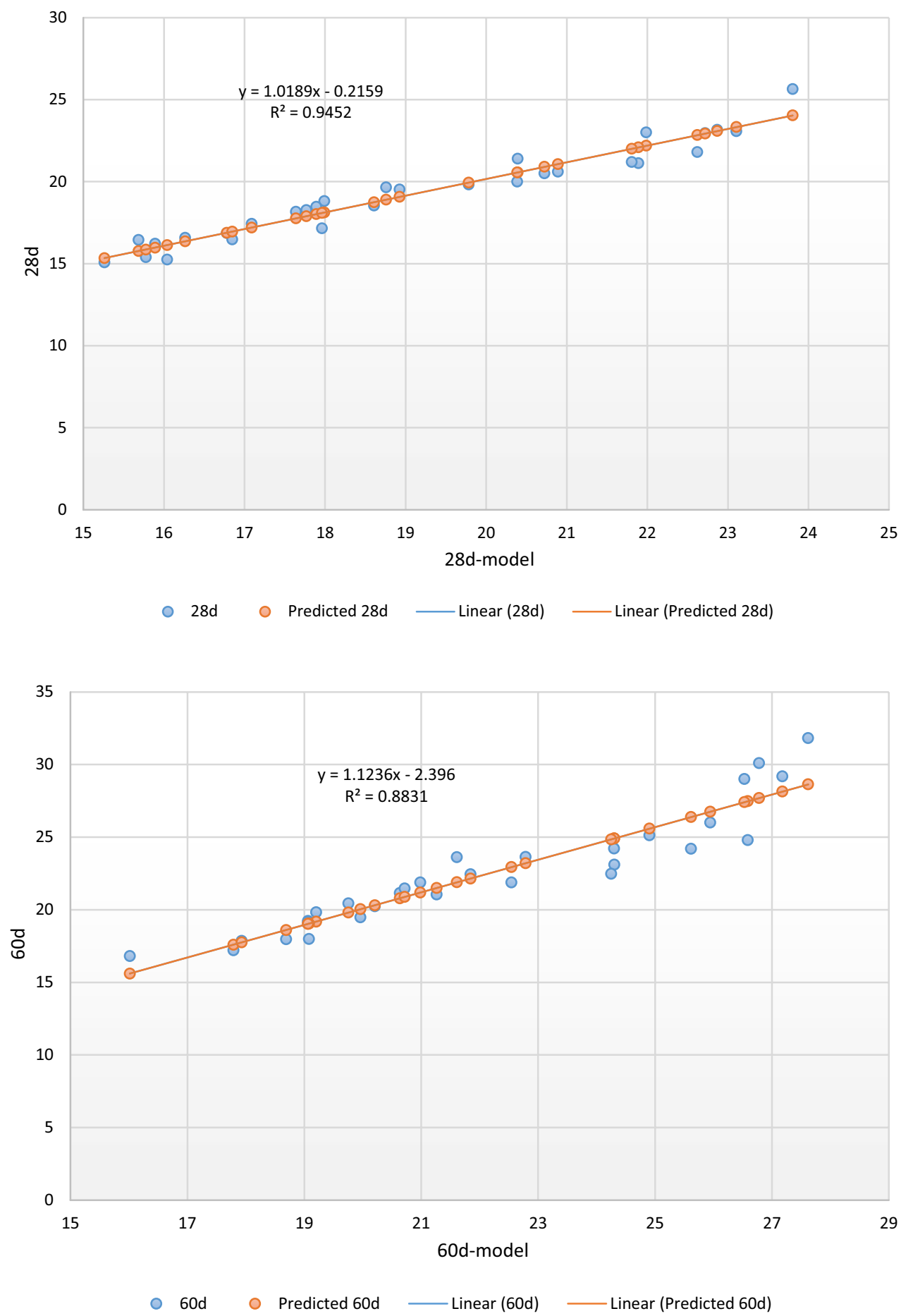

The regression model performance scored $86 \%$ and 6.35 for $R^{2}$ and RMSE, respectively, compared to 0.91 and 0.07 for $R^{2}$ and RMSE, respectively, of the ANN model. We can observe a better and improved performance which is a major advantage of neural network modelling and also taking into account nonlinear relationship of the variables.

\section{Conclusion}

Based on the findings of this investigation, the following conclusions can be drawn:

- The ANN model for predicting the mechanical properties of SDA and AW concrete performed well in 
Fig. 16 90-Day cured concrete compressive strength line of fit plot

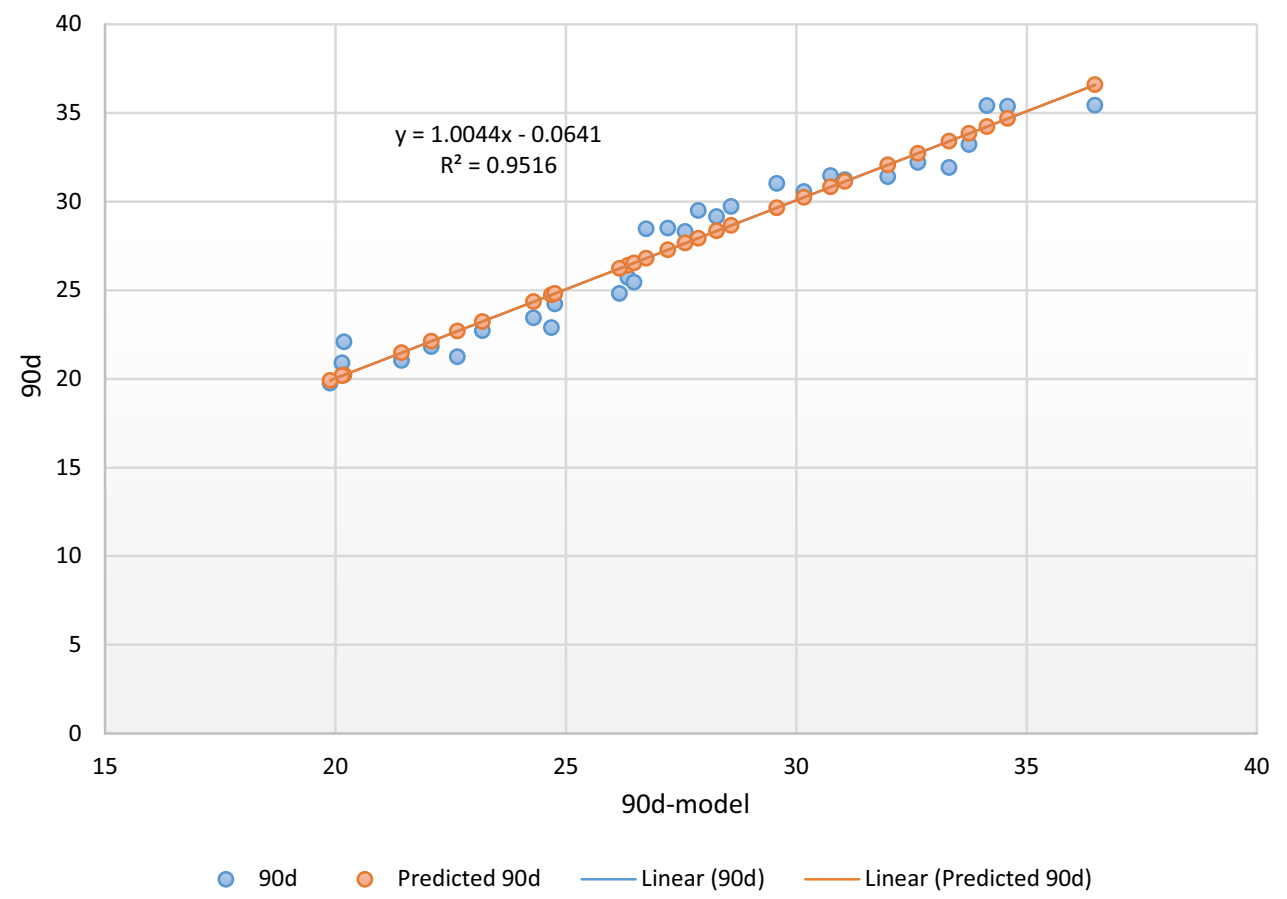

Table 5 Condition of model validity

\begin{tabular}{|c|c|c|c|c|}
\hline Output & $\begin{array}{l}\text { Statistical } \\
\text { param- } \\
\text { eter }\end{array}$ & Condition & $\begin{array}{l}\text { Results } \\
\text { obtained }\end{array}$ & Remarks \\
\hline \multirow[t]{2}{*}{ Initial ST } & $R$ & $>0.8$ & 0.9273 & Satisfactory \\
\hline & RMSE & $\begin{array}{l}\text { To be close } \\
\text { to } 0\end{array}$ & 0.142 & Good \\
\hline \multirow[t]{2}{*}{ Final ST } & $R$ & $>0.8$ & 0.8514 & Good \\
\hline & RMSE & $\begin{array}{l}\text { To be close } \\
\text { to } 0\end{array}$ & 0.0197 & Satisfactory \\
\hline \multirow[t]{2}{*}{$3 d$} & $R$ & $>0.8$ & 0.8597 & Good \\
\hline & RMSE & $\begin{array}{l}\text { To be close } \\
\text { to } 0\end{array}$ & 0.1623 & Good \\
\hline \multirow[t]{2}{*}{$7 d$} & $R$ & $>0.8$ & 0.9346 & Satisfactory \\
\hline & RMSE & $\begin{array}{l}\text { To be close } \\
\text { to } 0\end{array}$ & 0.0785 & Good \\
\hline \multirow[t]{2}{*}{$28 d$} & $R$ & $>0.8$ & 0.9452 & Satisfactory \\
\hline & RMSE & $\begin{array}{l}\text { To be close } \\
\text { to } 0\end{array}$ & 0.1062 & Good \\
\hline \multirow[t]{2}{*}{$60 d$} & $R$ & $>0.8$ & 0.8831 & Satisfactory \\
\hline & RMSE & $\begin{array}{l}\text { To be close } \\
\text { to } 0\end{array}$ & 0.0015 & Satisfactory \\
\hline \multirow[t]{2}{*}{$90 d$} & $R$ & $>0.8$ & 0.9516 & Good \\
\hline & RMSE & $\begin{array}{l}\text { To be close } \\
\text { to } 0\end{array}$ & 0.0346 & Satisfactory \\
\hline
\end{tabular}

predicting, the statistical parameter $R^{2}$ is 0.99997 , 0.99805 , and 0.9999 for training, testing and validation steps, respectively. The accuracy of the ANN model is due to the fact that the nonlinear relation between the input variables is considered. Therefore, the ANN is a reliable method for predicting mechanical properties of SDA and AW concrete.

- Due to their specific surface area and amorphous characteristics, both AW and SDA have remarkable pozzolanic activity and can therefore be used as SCM. This is because SCM added to concrete mix as a partial cement replacement can reduce the likelihood of ASR occurring as they reduce the alkalinity of the pore fluid thereby enhancing better performance.

- With the incorporation of SDA and AW as SCM by replacement, the setting time is shortened. This is due to the early formation of a large amount of $\mathrm{C}-\mathrm{S}-\mathrm{H}$ gel from hydration of $\mathrm{C}_{3} \mathrm{~S}$ and from the reaction of SDA residues and $\mathrm{Ca}(\mathrm{OH})_{2}$.

- The addition of SDA and AW residues increase the compressive strength of the concrete. The increase in strength is due to the fact that $\mathrm{Ca}(\mathrm{OH})_{2}$ diminished or wholly disappear and $\mathrm{C}-\mathrm{S}-\mathrm{H}$ increases.

- The root mean square error (RMSE) and $R$-value were used as yardstick and criterions for performance testing of the model. The results based on the conditions from Table 5 show a good correlation which means that the dependent variable can be predicted without error from the independent variable.

- Linear Regression was used in model validation with $86 \%$ and 6.35 for $R^{2}$ and RMSE, respectively, compared to 0.91 and 0.07 for $R^{2}$ and RMSE, respectively, of the ANN model which shows than ANN model performs better.

- The results obtained from the developed Artificial Neural Network model were compared with results from 
experimental studies. The average prediction to the experimental data were close when compared, indicating the ability of the model to predict concrete mix ratio accuracy and effectively.

\section{Compliance with ethical standards}

Conflict of interest There are no recorded conflicts of interests in this research work.

Open Access This article is distributed under the terms of the Creative Commons Attribution 4.0 International License (http://creativeco mmons.org/licenses/by/4.0/), which permits unrestricted use, distribution, and reproduction in any medium, provided you give appropriate credit to the original author(s) and the source, provide a link to the Creative Commons license, and indicate if changes were made.

\section{References}

1. Elinwa AU, Mahmood YA (2002) Ash from Timber Waste as cement replacement material. Cem Concr Compos 124(2):219-222

2. Werna OR (1994) Use of natural pozzolans in concrete. ACI Mater J 91(4):410-426

3. FHWA (2010-06-22) Alkali-silica reactivity (ASR)-concrete-pavements-FHWA. Alkali Silica Reactivity (ASR) Development and Deployment Program. Archived from the original on 8 August 2010. Retrieved 2010-07-28

4. Ichikawa T, Miura M (2007) Modified model of alkali-silica reaction. Cem Concr Res 37(9):1291-1297. https://doi.org/10.1016/j. cemconres.2007.06.008

5. Monnin Y, Dégrugilliers P, Bulteel D, Garcia-Diaz E (2006) Petrography study of two siliceous limestones submitted to alkalisilica reaction. Cem Concr Res 36(8):1460-1466. https://doi. org/10.1016/j.cemconres.2006.03.025

6. Terrence R, Thomas M, Gruber KA (2000) The effect of metakaolin on alkali-silica reaction in concrete. Cem Concr Res 30(3):339344. https://doi.org/10.1016/s0008846(99)00261-6

7. Snellings R, Mertens G, Elsen J (2012) Supplementary cementitious materials. Rev Mineral Geochem 74:211-278. https://doi. org/10.2138/rmg.2012.74.6

8. Pala M, Özbay E, Öztas A, Yuce MI (2007) Appraisal of long-term effects of fly and silica fume on compressive strength of concrete by neural networks. Constr Build Mater 21(2):384-394. https://doi.org/10.1016/j.conbuildmat.2005.08.009

9. Lee SC (2003) Prediction of concrete strength using artificial neural networks. Eng Struct 25(7):849-857

10. Trtnik G, Kavčič F, Turk G (2009) Prediction of concrete strength using ultrasonic pulse velocity and artificial neural networks. Ultrasonics 49(1):53-60

11. Ni HG, Wang JZ (2000) Prediction of compressive strength of concrete by neural networks. Cem Concr Res 30(8):1245-1250

12. Lai S, Serra M (1997) Concrete strength prediction by means of neural network. Constr Build Mater 11(2):93-98

13. Paulson AJ, Prabhavathy RA, Rekh S, Brindha E (2019) Application of neural network for prediction of compressive strength of silica fume concrete. Int. J. Civ. Eng. Technol. (IJCIET) 10(2):1859-1867

14. al-Swaidani AM, Khwies WT (2018) Applicability of artificial neural networks to predict mechanical and permeability properties of volcanic scoria-based concrete. Adv Civ Eng 2018, 5207962. https://doi.org/10.1155/2018/5207962

15. Ayat $\mathrm{H}$, Kellouche $\mathrm{Y}$, Ghrici M, Boukhatem B (2018) Compressive strength prediction of limestone filler concrete using artificial neural networks. Adv Comput Des 3(3):289-302. https:// doi.org/10.12989/acd.2018.3.3.289

16. Goktepe AB, Inan G, Ramyar K, Sezer A (2006) Estimation of sulfate expansion level of PC mortar using statistical and neural approaches. Constr Build Mater 20(7):441-449

17. Kiran S, Lal B (2016) Modeling of soil shear strength using artificial neural network approach. Electron J Geotech Eng 21:3751-3771

18. Sebastia M, Fernandez Olmo I, Irabien A (2003) Neural network prediction of unconfined compressive strength of coal fly-ash cement mixtures. Cem Concr Res 33:1137-1146

19. Lai S, Sera M (1997) Concrete strength prediction by means of neural network. Constr Build Mater 11:93-98

20. Mohammadhassani $M$, Nezamabadi-Pour $H$, Jumaat $M Z$, Jameel M, Arumugam AMS (2013) Application of artificial neural networks (ANNs) and linear regressions (LR) to predict the deflection of concrete deep beams. Comput Concr 11(3):237-252

21. Cladera A, Mari R (2004) Shear Design Procedures for reinforced normal and high strength concrete beams using artificial neural network beams. I: beams without stirrups. Eng Struct 26(7):917-926

22. Kartam N, Flood I, Garrett JH (1997) Artificial neural networks for civil engineers: fundamentals and applications. ASCE, New York

23. Yeh IC (1998) Modeling of strength of high-performance concrete using artificial neural networks. Cem Concr Res 28:1797-1808

24. Topcu IB, Sarıdemir M (2008) Prediction of mechanical properties of recycled aggregate concretes containing silica fume using artificial neural networks and fuzzy logic. Comput Mater Sci 42(1):74-82

25. Shahin MA (2013) Artificial intelligence in geotechnical engineering: applications, modeling aspects, and future directions. In: Yang X, Gandomi AH, Talatahari S, Alavi AH (eds) Metaheuristics in water, geotechnical and transport engineering. Elsevier Inc., London, pp 169-204

26. Bouasker M, Khalifa NEH, Mounanga P, Kahla NB (2014) Earlyage deformation and autogenous cracking risk of slag-limestone filler-cement blended binders. Construct Build Mater 55:158-167

27. Flood I, Kartam N (1994) Neural network in civil engineering II: systems and applications. J Comput Civ Eng ASCE 8(2):149-162

28. Chandwani V, Agrawal V, Nagar R (2013) Applications of soft computing in civil engineering: a review. Int J Comput Appl 81(10):13-20

29. Lazarevska M, Trombeva GA, Knezevic M, Samardzioska T, Cvetkovska M (2012) Neural network prognostic model for RC beams strengthened with CFRP strips. Appl Eng Sci 10:27-30

30. Khademi F, Jamal SM, Deshpande N, Londhe S (2016) Predicting strength of recycled aggregate concrete using artificial neural network, adaptive neuro-fuzzy inference system and multiple linear regression. Int J Sustain Built Environ 5(2):355-369

31. Nath UK, Goyal MK, Nath TP (2011) Prediction of compressive strength of concrete using neural network. Int J Emerg Trends Eng Dev 1(1):32-43

32. Zain MFM, Suhad MA, Hamid R, Jamil M (2010) Potential for utilizing concrete mix properties to predict strength at different ages. J Appl Sci 10:2831-2838 
33. Udhaya Kumar V, Bharat Kumar BH, Balasubramanian K, Krishna Moorthy TS (2007) Applications of neural networks for concrete strength prediction. Indian Concr J 2007:13-17

34. Kheder GF, Al-Gabban AM, Suhad MA (2003) Mathematical model for the prediction of cement compressive strength at the ages of 7 and 28 days within 24 hours. Mater Struct 36:693-701

35. Kim Jl, Kim DK, Feng MQ, Yazdani F (2004) Application of neural networks for estimation of concrete strength. J Mater Civ Eng 16(3):257-264

36. Bandyopadhyay G, Chattopadhyay S (2007) Single hidden layer artificial neural network models versus multiple linear regression model in forecasting the time series of total ozone. Int J Environ Sci Technol 4(1):141-149

37. Werbos PJ (1988) Generalization of backpropagation with application to a recurrent gas market model. Neural Networks 1(4):339-356

38. Todd CPD, Challis RE (1999) Quantitative classification of adhesive bondlines using Lamb waves and artificial neural networks. IEEE TransUFFC 46(1):167-181

39. Graupe D, Abon J (2002) "A neural network for blind adaptive filtering of unknown noise from speech. Intell Eng Syst Artif Neural Netw 12:683-688

40. Rencher AC, Christensen WF (2012) Chapter 10, Multivariate regression-Section 10.1, introduction. In: Methods of multivariate analysis, Wiley Series in Probability and Statistics, 709, 3rd ed. Wiley, New York. ISBN 9781118391679

41. Salahudeen AB, Ijimdiya TS, Eberemu AO, Osinubi KJ (2018) Artificial neural networks prediction of compaction characteristics of black cotton soil stabilized with cement kiln dust. J Soft Comput Civ Eng 2(3):53-74

42. Wu W, Guozhi W, Yuanmin Z, Hongling W (2009) Genetic algorithm optimizing neural network for short-term load forecasting. In: International forum on information technology and applications, 2009, pp 583-585. https://doi.org/10.1109/ifita .2009 .326
43. Whitley D, Starkweather T, Bogart C (1990) Genetic algorithms and neural networks: optimizing connections and connectivity. Parallel Comput 14(3):347-361. https://doi. org/10.1016/0167-8191(90)90086-o

44. Tapkin S, Ariöz O, Tuncan M, Tuncan A, Ramyar K (2006) Use of neural networks for the evaluation of concrete core strengths. In: 4th faculty of architecture and engineering international symposium, European University of Lefke, Turkey, pp 195-202

45. Popovics S (1998) History of a mathematical model for strength development of Portland cement concrete. $\mathrm{ACI}$ Mater J 95(5):593-600

46. MathWorks Inc. (2015) MATLAB the language of technical computing. Version 8.5, Natick, MA, USA

47. Pakbaz HHMS, Mehdizadeh R (2015) Comparison and evaluation of artificial neural network (ANN) training algorithms in predicting soil type classification. Bull Environ Pharmacol Life Sci 4(1):212-218

48. Alaneme George U, Mbadike Elvis M (2019) Optimization of flexural strength of palm nut fibre concrete using Scheffe's theory. Mater Sci Energy Technol 2:272-287. https://doi. org/10.1016/j.mset.2019.01.006

49. BS 12 (1978) Specification for ordinary and rapid hardening Portland cement. British Standard Institute of London, London

50. ASTM C191 Standard test method for time of setting of hydraulic cement by Vicat needle

51. Colin Cameron A, Windmeijer FAG (1997) An R-squared measure of goodness of fit for some common nonlinear regression models. J Econom 77(2):1790. https://doi.org/10.1016/s0304 -4076(96)01818-0

52. Ritter A, Muñoz-Carpena R (2013) Performance evaluation of hydrological models: statistical significance for reducing subjectivity in goodness-of-fit assessments. J Hydrol 480(1):3345. https://doi.org/10.1016/j.jhydrol.2012.12.004

Publisher's Note Springer Nature remains neutral with regard to jurisdictional claims in published maps and institutional affiliations. 